\title{
A comparison of methods for increasing compliance within a general practitioner based screening project for colorectal cancer and the effect on practitioner workload
}

\author{
G PYE, ${ }^{1}$ M CHRISTIE, ${ }^{1} \mathrm{~J}_{\text {O CHAMBERLAIN },{ }^{2} \mathrm{~S} M \text { MOSS },{ }^{2} \text { AND J D HARDCASTLE }}{ }^{1}$ \\ From the Department of Surgery, ${ }^{1}$ University of Nottingham and the Institute of Cancer Research, ${ }^{2}$ Royal Marsden \\ Hospital, Surrey.
}

SUMMARY Screening for colorectal cancer by testing for faecal occult blood (FOBT) is effective for early diagnosis, but the success of a screening programme also depends on compliance. The aims of this study were to assess the effect of health education on compliance and to assess any addition to general practitioner workload that resulted. Altogether 3860 patients were recruited and randomly allocated to test or control group. The test group was further divided into subgroups, some of which received health education. Compliance with FOBT was $54.7 \%(210 / 384)$ in the subgroup receiving only the doctor's letter, which fell to $48 \cdot 1 \%(743 / 1544)$ in the group receiving health education. General practitioner consultation rates were similar in test and control groups.

Colorectal cancer is the second most common cause of death from malignant disease in England and Wales. ${ }^{1}$ Results of treatment are disappointing and less than half of the patients undergoing apparently curative resection will be alive five years later. ${ }^{2}$ It is possible that the early detection of these tumours, particularly in the asymptomatic stage, may result in a better prognosis. 45

Screening for colorectal cancer by testing for occult blood in the faeces has been shown to be feasible and to be capable of detecting carcinomas, many of which are localised to the bowel wall (Dukes' stage A). ${ }^{67}$ The test can also detect large adenomas which have a potential for malignant change ${ }^{8}$ whose removal may prevent the subsequent development of invasive cancer. Many studies of screening for colorectal cancer have used selected groups of volunteers who have been offered screening at the time of annual health checks or during other contact with the medical services. ${ }^{910}$ Although this form of recruitment may be effective, any results obtained from these studies do not relate to the population as a whole. The challenge of reducing the mortality from colorectal neoplasia must be tackled by offering screening to the whole population, and one of the major influences on the success or otherwise of population screening is the extent to which the population at risk agrees to participate. Some previous surveys have indicated that among British populations aged over 40 , the response to a mailed invitation to do such a test was of the order of $40 \%$, but when the invitation was preceded by written and pictorial information about large bowel cancer compliance rose to $50 \% .^{711}$ Another, however, found that the addition of educational material had no effect on response. ${ }^{12}$ There is still doubt, therefore, whether compliance may be improved by providing health education in addition to the test kit.

Similarly, it is not clear whether a better response would be obtained by sending the educational material a short time before the test kit, with the intention of making the subject think more about the possibility of bowel cancer and hence be in a more receptive frame of mind, or whether the simpler alternative of sending the educational material with the test kit is equally good. Studies of reasons for participation or nonparticipation in cancer screening suggest that a person's perception of his own vulnerability to cancer is a major influence in promoting compliance, ${ }^{13}$ and the education therefore must stress his susceptibility to it, as well as the improvement in prognosis which may be associated with early detection.

Faecal occult blood testing requires the collection of a small stool sample, and this may be a factor which reduces compliance. A simpler and more acceptable screening method might be an enquiry about relevant bowel symptoms. However, some studies have shown that symptoms of rectal bleeding, change in bowel habit, and abdominal pain are too non-specific to be useful for screening. Moreover, duration of symptoms bears little relation to pathological stage of colorectal 
cancer, ${ }^{14}$ implying that recent onset of symptoms may not be associated with an early stage cancer. In one study, questions about these symptoms have been shown to be very insensitive in detecting neoplasia, compared with occult blood testing of the same individuals. ${ }^{15}$ Another study, however, which used more specifically worded questions among a group of people at work, concluded that a history of bleeding, especially if dark, was of comparable sensitivity to occult blood testing in the detection of adenomas. ${ }^{16}$

The prevalence of recent bowel symptoms in middle aged people may be as high as $25 \%{ }^{15}$ but not all of them are reported to the general practitioner. ${ }^{17}$ The general practitioner workload attributable to these non-specific symptoms is unknown. One possible consequence of alerting people to their vulnerability to colorectal cancer, either by health education or by sending them an occult blood test kit, could be to prompt additional general practitioner consultations and thereby cause an increase in their workload.

The principal aim of the study was to investigate the effect of different methods of increasing compliance within a population based faecal occult blood screening study. In addition we wanted to assess the response to a bowel symptom questionnaire and to determine the yield of disease detected by it and also to determine whether the rate of general practitioner consultations for bowel related problems in a sample of people aged 50-74 years was altered by increasing their awareness of bowel disease by offering faecal occult blood testing kits with or without educational material.

\section{Patients and methods}

The Nottingham population based screening project for colorectal cancer ${ }^{6}$ is conducted in partnership with local general practitioners. In each participating practice a list was compiled of registered people aged 50-74 years and these were then randomised, by household, into a test group to receive faecal occult blood tests (Haemoccult), and a control group. Faecal occult blood tests were sent to those in the test group together with an explanatory letter signed by the general practitioner, explaining the test. In two practices a randomised trial of educational leaflets and bowel symptom questionnaires as a means of increasing compliance was conducted.

Altogether 3860 people were recruited and randomised into equal sized test and control groups. The test group was further randomised into five equal groups as follows:

Group 1 received faecal occult blood tests together with the usual doctor's letter.

Group 2 received the faecal occult blood test and the doctor's letter together with an educational leaflet.

Group 3 again received the usual faecal occult blood test and doctor's letter together with a bowel symptom questionnaire.

Group 4 received the educational leaflet two weeks prior to the faecal occult blood test and doctor's letter.

Group 5 received the bowel symptom questionnaire two weeks prior to the faecal occult blood test and doctor's letter.

The educational leaflet (fig 1) emphasised the importance of early detection of colorectal cancer and the associated improved prognosis if detected at an asymptomatic stage, and the bowel symptom questionnaire comprised questions about change in bowel habit, abdominal pain, and rectal bleeding. Individuals were not asked to avoid red meat prior to performing the Haemoccult test as it was felt that this would have an adverse effect on compliance. However, if the initial test was positive then it was repeated with dietary restrictions as recommended by the manufacturers.

Records were kept of returned faecal occult blood tests and questionnaires, and compliance rates were calculated for each group. General practitioner workload was monitored by recording the number and nature of general practitioner consultations by all patients in the test and control groups over the ten week study period. The preliminary educational leaflets and bowel symptom questionnaires (groups 4 and 5) were sent out during week 2 of the study, and all the faecal occult blood tests were sent out during week 4. In addition, the number of enquiries in person or by telephone to the general practitioner's reception staff arising from the screening study were recorded.

All patients with positive faecal occult blood tests were investigated by colonoscopy, supplemented by double contrast barium enema if the endoscopic examination was incomplete. Those who reported recent rectal bleeding yet had negative faecal occult blood tests underwent flexible fibreoptic sigmoidoscopy to $60 \mathrm{~cm}$. If any adenomas were detected full colonoscopy and polypectomy was performed.

\section{Results}

COMPLIANCE WITH FAECAL OCCULT BLOOD TESTING

The compliance with faecal occult blood testing for the five groups is given in table 1 . For each practice the compliance was no greater in groups 2 to 5 than in group 1 who received just the test kit plus a doctor's letter signed by their own GP. In practice 1 , there was 


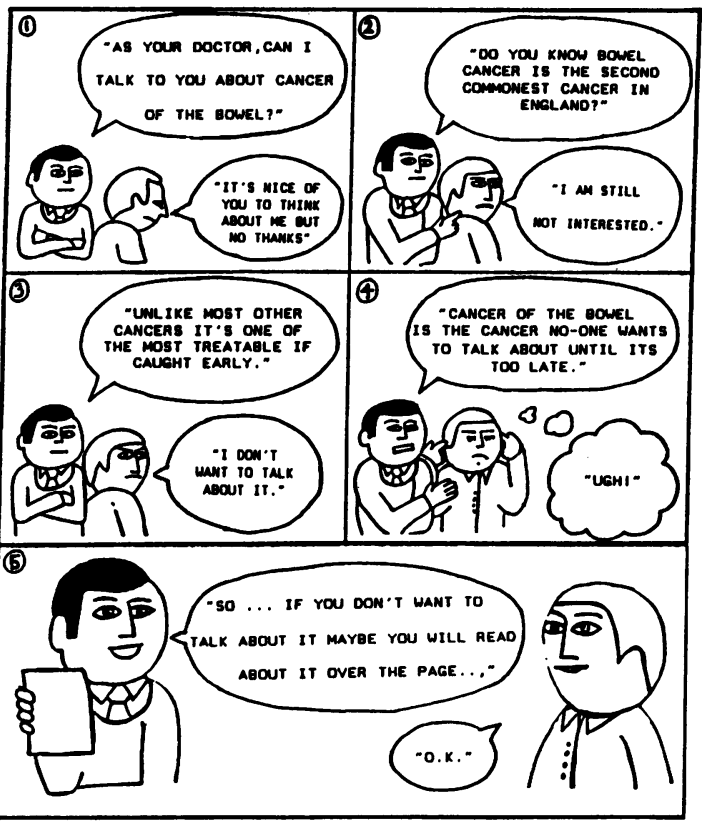

Cancer of the bowel is a serious problem

Most people go to their GP when its too late and treatment involves a major operation. This is because the symptoms of bowel cancer occur when it is in its final stage. Unfortunately however only one person in four can be cured by this time.

\section{Fig 1 Educational leaflet}

no statistically significant difference in compliance between any of the groups but in practice 2, compliance was significantly lower in groups 2 to 5 than in group 1, implying that, if anything, the educational leaflet and questionnaire had an adverse effect. There was no statistically significant difference in compliance between those who received the questionnaire two weeks before the faecal occult blood test and those who received it at the same time. No significant difference was found in compliance between men and women.

Table 1 Compliance rates for faecal occult blood screening

\begin{tabular}{lccccc}
\hline & Group 1 & Group 2 & Group 3 & Group 4 & Group 5 \\
\hline Practice 1 & $58 \%$ & $55 \%$ & $52 \%$ & $58 \%$ & $58 \%$ \\
& $(79 / 136)$ & $(76 / 136)$ & $(72 / 137)$ & $(80 / 137)$ & $(79 / 135)$ \\
*Practice 2 & $53 \%$ & $40 \%$ & $45 \%$ & $47 \%$ & $42 \%$ \\
& $(131 / 249)$ & $(100 / 248)$ & $(113 / 250)$ & $(117 / 251)$ & $(106 / 250)$ \\
"Combined & $55 \%$ & $46 \%$ & $48 \%$ & $51 \%$ & $48 \%$ \\
& $(210 / 385)$ & $(176 / 385)$ & $(185 / 387)$ & $(197 / 388)$ & $(185 / 385)$ \\
\hline
\end{tabular}

* Group 1 cf Groups 2-5; $\chi^{2}=18.0, p<0.001$
The value of early detection

People with small early cancers or "polyps", which are growths that can turn into cancers, can often be cured without an operation. This can be done by simply removing them from inside the bowel.

\section{Why should I worry?}

Unfortunately, small tumours often do not produce symptoms and many people have no problems until the tumours have grown too large and a cure is very difficult.

\section{What can I do about this?}

The majority of polyps and cancers bleed even at an early stage. The amount of blood lost may be so small that the patient would be unlikely to notice it. $A$ new test has been designed to detect this unseen blood in the bowel motion.

Already many people in Nottinghamshire have been tested in this way. Most have been reassured, but of the small tumours that have been found the majority were removed without a major operation.

\section{Why me?}

You are over the age of 50 , when there is an increased risk of developing this cancer.

\section{Whore can thle test be done?}

Here is the opportunity to perform this test. The test is free, simple to perform and can be done in the privacy of your own home. The result is entirely confidential.

Please do not throw it away. Do itt

It could save you a great deal of worry and inconvenience later on.

COMPLIANCE WITH BOWEL SYMPTOM QUESTIONNAIRE

For the practices combined, the compliance with the bowel symptom questionnaire was $77 \%$ in group 5 compared to $50 \%$ in group 3 (table 2). The response was therefore much higher to the questionnaire when sent in advance of the faecal occult blood kit, implying that a substantial proportion of subjects were prepared to fill in the questionnaire but not if they were asked to complete a faecal occult blood test at the Table 2 Compliance with bowel symptom questionnaire

\begin{tabular}{lcc}
\hline & Group 3 & Group 5 \\
\hline Practice 1 & $58 \% *$ & $87 \% *$ \\
& $(80 / 137)$ & $(118 / 135)$ \\
Practice 2 & $45 \% \dagger$ & $71 \% \dagger$ \\
& $(113 / 250)$ & $(177 / 250)$ \\
Combined & $50 \% \pm$ & $77 \% \pm$ \\
& $(193 / 387)$ & $(295 / 385)$ \\
\hline
\end{tabular}

$x^{2}=28.9, \mathrm{p}<0.001$

$+\chi^{2}=33.6, \mathrm{p}<0.001$

$\pm \chi^{2}=59.4, \mathrm{p}<0.001$ 
same time. Altogether there were 138 subjects who, although willing to complete the bowel symptom questionnaire, were not prepared to do the stool test, but just 20 subjects who failed to complete the questionnaire although they completed the stool test (table 3).

\section{THE EFFECT ON GENERAL PRACTITIONER} WORKLOAD

The number of surgery consultations for all reasons over the ten week study period by all patients in the test and control groups is given in table 4 . An average of 40 consultations for all symptoms per 1000 patients in the

Table 3 Number of patients completing faecal occult blood test and/or bowel symptom questionnaire, groups 3 and 5 combined

\begin{tabular}{lccc}
\hline & $\begin{array}{l}\text { Questionnaire } \\
\text { completed }\end{array}$ & $\begin{array}{l}\text { Questionnaire } \\
\text { not completed }\end{array}$ & Totals \\
\hline $\begin{array}{l}\text { F O B test } \\
\text { completed }\end{array}$ & 350 & 20 & 370 \\
$\begin{array}{l}\text { F O B test } \\
\text { not completed }\end{array}$ & 138 & 264 & 402 \\
\begin{tabular}{l} 
Totals \\
\hline
\end{tabular} & 488 & 284 & 772 \\
\hline
\end{tabular}

Table 4 General practitioner consultation rates-all symptoms-ten week study period - patients aged 50-74 years

\begin{tabular}{llll}
\hline & $\begin{array}{l}\text { Consultations } \\
\text { per week }\end{array}$ & $\begin{array}{l}\text { No patients } \\
\text { aged 50-74 }\end{array}$ & $\begin{array}{l}\text { Cons } / w k / 1000 \\
\text { aged 50-74 }\end{array}$ \\
\hline Practice 1 & 53 & 1360 & 39 \\
Practice 2 & 103 & 2500 & 41 \\
Combined & 156 & 3860 & 40 \\
\hline
\end{tabular}

age range 50-74 years per week was recorded over the 10 week study period. The consultations relating only to lower gastrointestinal symptoms (constipation, diarrhoea, abdominal pain, rectal bleeding) were recorded and shown in table 5. A rate of 1.5 consultations per week per 1000 patients aged 50-74 years for bowel related symptoms was recorded. These represent less than $4 \%$ of the routine consultations of patients in this age group.

To detect any effect of the screening study on this consultation rate the test group (all persons in groups 1 to 5) and control group weekly rates were calculated and compared. The preliminary educational leaflets and bowel symptom questionnaires (groups 4 and 5) were despatched in week 2 , and the faecal occult blood test kits were despatched to all test groups during week 4. Results are shown in figure 2 . Over the ten week period there was no significant difference in consultation rates for bowel related symptoms between the test and control groups.

There were some enquiries to practice reception staff about the faecal occult blood tests mainly checking administrative details or asking about diet and drug therapy during the test period (table 6). Several patients were curious to know if they had been specially singled out for screening. None of the

Table 5 General practitioner consultation rates-bowel symptoms-ten week study period-patients aged 50-74

\begin{tabular}{lllll}
\hline & $\begin{array}{l}\text { Consultations/wk } \\
\text { All symptoms }\end{array}$ & $\begin{array}{l}\text { Consultations/wk } \\
\text { Bowel symptoms }\end{array}$ & $\begin{array}{l}\text { Percentage } \\
\text { bowel }\end{array}$ & $\begin{array}{l}\text { Bowel cons/wk } \\
\text { per } 1000\end{array}$ \\
\hline Practice 1 & 53 & 2.0 & 3.8 & 1.5 \\
Practice 2 & 103 & 3.7 & 3.6 & 1.5 \\
Combined & 156 & 5.7 & 3.6 & 1.5 \\
\hline
\end{tabular}

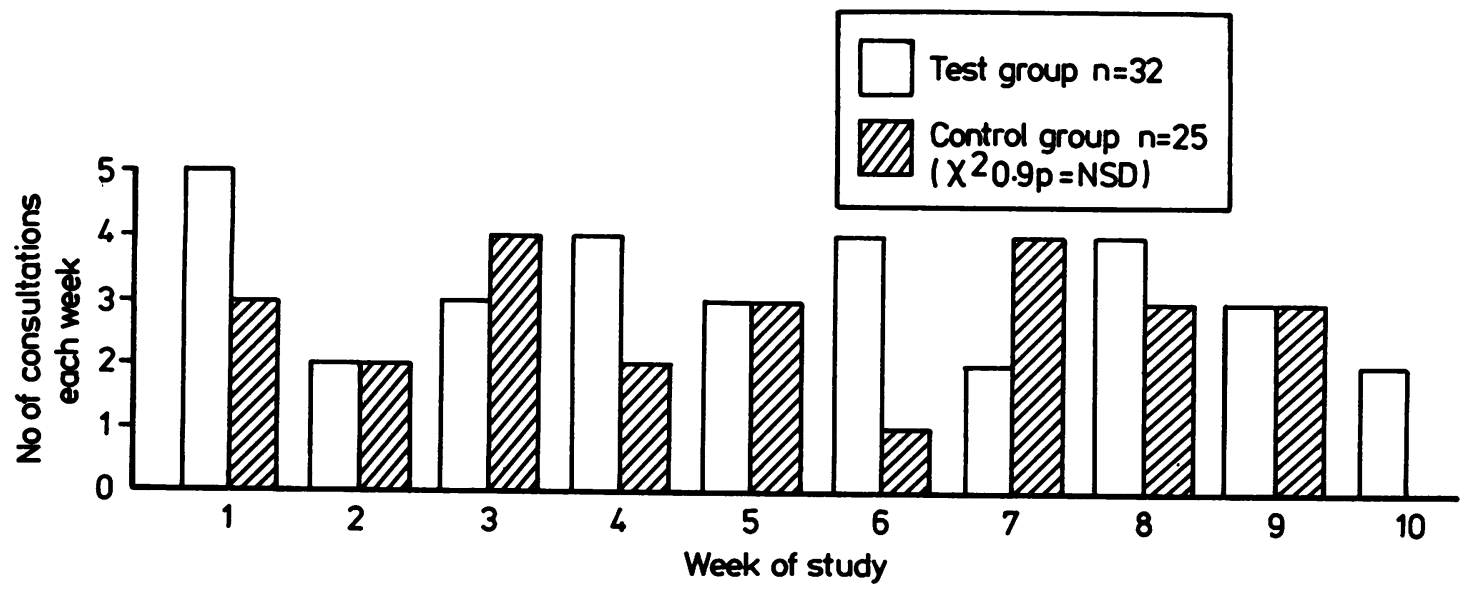

Fig 2 Consultation rates over 10 week study period 
Table 6 Total screening study related enquiries, ten week study period

\begin{tabular}{lll}
\hline & Telephone & Personal calls \\
\hline Practice 1 & 1 & 4 \\
Practice 2 & 5 & 8 \\
Combined & 6 & 12 \\
\hline
\end{tabular}

enquiries required referral to the general practitioner as the reception staff, who had been briefed in advance on the study protocol, were able to deal with the queries.

\section{PATHOLOGY DETECTED}

Of the 953 patients completing faecal occult blood testing, 15 were positive $(1.6 \%)$ and 14 of these agreed to undergo investigation. This is consistent with previous practices studied. The yield of disease from this group was three patients with sigmoid adenoma larger than $1.0 \mathrm{~cm}$, representing $21 \%$ of those investigated or a rate of 3 per 1000 of those completing the test. Of those 488 completing the bowel symptom questionnaire, $61(23 \%)$ indicated an episode of rectal bleeding. Review of their general practitioner notes revealed that $33(54 \%)$ had not attended their general practitioner in the past two years with either lower gastrointestinal symptoms or rectal bleeding. Twenty eight (46)\% had reported lower gastrointestinal symptoms and of these only $14(23 \%)$ had mentioned rectal bleeding. Fifty eight of the 61 reporting rectal bleeding agreed to undergo investigation which detected three with adenomas larger than $1.0 \mathrm{~cm} \mathrm{(2}$ rectal and 1 sigmoid), representing $5.2 \%$ of those investigated or a rate of $6 \cdot 1 / 1000$ of those completing the questionnaire. In all three cases the faecal occult blood test had been negative, and they had not previously reported bowel symptoms or rectal bleeding to their family practitioner. In the study as a whole, $1.6 \%$ of patients completing the faecal occult blood test required investigation compared with $12.5 \%$ of those completing the bowel symptom questionnaire.

\section{Discussion}

Neither educational material nor bowel symptom questionnaires increased compliance in this study and in one practice seemed to have a deleterious effect. These findings are similar to those of Nicholls et al. ${ }^{12}$ The timing of the additional literature was unimportant in altering the compliance with faecal occult blood testing. The compliance achieved in group $1(55 \%)$ is in excess of many previously reported figures. $^{6711}$ It may be that the doctor's letter recruits all those susceptible to postal recruitment and there may be little scope for further improvement. Indeed, it may be that by receiving educational material not aimed specifically at them, the feeling of a personal invitation was lost and therefore the possibility of individual benefit seemed so small as to make the relative ordeal of investigation appear unattractive. Readiness to complete the bowel symptom questionnaire was much greater when it was sent prior to the faecal occult blood tests $(77 \%)$ than when they were sent together $(50 \%)$.

Practice 1 had a consistently higher compliance rate than practice 2 . There are several factors which may influence compliance with screening including age, sex, socioeconomic class, and attitudes toward the general practitioner and health issues in general. ${ }^{17}$ There were no gross differences in age and sex distribution between the practices but full demographic data were not collected.

The general practitioner consultation rate for all symptoms in the study group was 40 per week per 1000 patients aged $50-74$ years. Of these only $3.6 \%$ related to symptoms attributable to the lower gastrointestinal system, which therefore form only a small part of the routine work of the general practitioner for patients in this age group. This rate of 1.5 consultations per week per 1000 patients aged 50-74 was not significantly increased by the performance of the screening study including the use of educational leaflets and bowel symptom questionnaires. The screening study related enquiries that did occur were few in number and were of such a nature (largely administrative or concerning details of the study protocol) that appropriately briefed practice reception staff were more than able to deal with them effectively.

Whereas the compliance with the bowel symptom questionnaire may be greater than to faecal occult blood testing the predictive value of reporting 'rectal bleeding' for diagnosis of colorectal adenomas was only $5 \cdot 2 \%(3 / 58)$ compared with $21 \%(3 / 14)$ for faecal occult blood tests $(p<0.05)$. Therefore largenumbers of patients would undergo negative investigations if these were based on the report of rectal bleeding from such a questionnaire in the presence of a negative faecal occult blood test. If patients attending their general practitioner with recent onset of rectal bleeding are investigated then there may be a prevalence of colorectal cancer up to $10 \%$ but this is clearly a different group from a population based screening study. ${ }^{18}$ The detection rate of the three adenomas from 61 symptomatic patients $(5 \cdot 2 \%)$ was no greater than that reported in asymptomatic individuals in this age group. ${ }^{19}$

A personal letter from the family practitioner achieved a satisfactory compliance to faecal occult blood testing in this study, and the addition of any 
further educational literature only served to detract from it.

Compliance with the bowel symptom questionnaire was higher than for faecal occult blood tests but the questionnaire was unsuitable as a screening test because of its low specificity for colorectal neoplasia.

General practitioner consultations arising from lower gastrointestinal symptoms form only a small part of their routine workload from patients in the age group 50-74 years, and this was not significantly increased by participation in the general practitioner based population screen study for colorectal cancer, with or without additional educational literature. A small number of administrative enquiries were generated by this study but these were dealt with by practice reception staff.

We are greatly indebted to Mrs C Mangham for her administrative support throughout this study. Our thanks go to Drs McCoach, Brown, Phillipson, Buckell, Barrett, Sandilands, Bennett, Winterbottom, Jones, Duncan, and Perko who agreed to this study being conducted in their practices, and to their administrative and reception staff. This study was supported by a grant from the Cancer Research Campaign and the main trial of colorectal screening on which it was based is supported by the Medical Research Council.

\section{References}

${ }^{1}$ Registrar General Statistical Review of England and Wales, 1972-73. London: HMSO

2 Stower MJ, Hardcastle JD. The results of 1115 patients with colorectal cancer treated over an 8-year period in a single hospital. Eur J Surg Onc 1985: 11: 119-23.

${ }^{3}$ Gill PG, Morris PJ. The survival of patients with colorectal cancer treated in a regional hospital. Br J Surg 1978, 65: 17-20.
${ }^{4}$ Sherlock P, Winawer SJ. The role of early diagnosis in controlling large bowel cancer. Cancer 1977: 40: 22609-15.

${ }^{5}$ Gilbertsen VA, Nelms J. The prevention of invasive cancer of the rectum. Cancer 1978: 41: 1137-9.

${ }^{6}$ Hardcastle JD, Farrands PA, Balfour TW, Chamberlain J, Amar SS, Sheldon MG. Controlled trial of faecal occult blood testing in the detection of colorectal cancer. Lancet 1983: ii: $1-4$.

${ }^{7}$ Hardcastle JD, Armitage NC, Chamberlain J, Amar SS, James PD, Balfour TW. Faecal occult blood screening for colorectal cancer in the general population; results of a controlled trial. Cancer 1986: 58: 397-403.

${ }^{8}$ Morson BC. The polyp cancer sequence in the large bowel. Proc Roy Soc Med 1974: 67: 451-7.

9 Sontag SJ. Faecal occult blood screening for colorectal cancer in a Veterans Administration Hospital. Am J Surg 1983: 145: 89-94.

${ }^{10}$ Winawer SJ, Andrews M, Flehinger B, Sherlock P, Schottenfield D, Miller DG. Progress report on controlled trial of faecal occult blood testing for the detection of colorectal neoplasia. Cancer 1980: 45(12): 2959-64.

${ }^{11}$ Lallemand RC, Vakil PA, Pearson P, Box V. Screening for asymptomatic bowel cancer in general practice. $\mathrm{Br}$ Med J 1984: 288: 31-3.

12 Nichols S, Koch E, Lallemand RC, et al Randomised trial of compliance with screening for colorectal cancer. $\mathrm{Br}$ Med J 1986: 293: 107-10.

${ }^{13}$ Becker MH, Haefner DP, Kasl SV, Kirscht JP, Malman LA, Rosenstock IM. Selected psychocial models and correlates of individual health related behaviour. Medical Care 1977: 15: Supplement, 27-45.

${ }^{14}$ Holliday $H$, Hardcastle JD. Delay in diagnosis and treatment of symptomatic colorectal cancer. Lancet 1979: i: $309-11$.

${ }^{15}$ Farrands PA, Hardcastle JD. Colorectal screening by a self-completion questionnaire. Gut 1984: 25: 445-7.

${ }^{16}$ Silman AJ, Mitchell P, Nicholls RJ, et al. Self-reported dark red bleeding as a marker comparable with occult blood testing in screening for large bowel neoplasms. $B r J$ Surg 1983: 70: $721-4$.

${ }^{17}$ Farrands PA, Hardcastle JD, Chamberlain J, Moss SM. Factors affecting compliance with screening for colorectal cancer. Community Medicine 1984: 6: 12-9.

18 Goulston KJ, Cook I, Dent OF. How important is rectal bleeding in the diagnosis of bowel cancer and polyps? The Lancet August 1986: 261-5.

19 Wherry DC. Screening for colorectal neoplasia in asymptomatic patients using flexible fibreoptic sigmoidoscopy. Dis Colon \& Rectum 1981: 24: 521-2.

Accepted for publication September 1987 